\title{
A Study To Determine Various Parameters of An Alleged Fabricated Injury
}

\author{
Dr. Kuldip Kumar ${ }^{1}$, Dr. Manpreet $\mathrm{Kaul}^{2}$, Dr. Deep Rattan Mittal ${ }^{3}$, \\ Dr. Swati Tyagi ${ }^{4}$, Dr. Chanpreet Kaur Pawar ${ }^{5}$, Dr. Ashwani Kumar ${ }^{6}$, \\ Dr. Nirapjeet Kaur ${ }^{7}$ \\ ${ }^{1}$ Assistant Professor, Department Of Forensic Medicine \& Toxicology, Govt. Medical College, Amritsar . \\ ${ }^{2}$ Lecturer,Department Of Forensic Medicine \& Toxicology, Govt. Medical College, Amritsar. \\ ${ }^{3,4}$ Junior Resident, Department Of Forensic Medicine \& Toxicology, Govt. Medical College, Amritsar \\ ${ }^{5}$ Senior Resident, Department Of Forensic Medicine \& Toxicology, Govt. Medical College, Amritsar. \\ ${ }^{6}$ Assistant Prof. Department Of Surgery, Govt. Medical College, Amritsar. \\ ${ }^{7}$ Assistant Prof. Department Of Pedodontics \& Preventive Dentistry, Govt. Dental College, Amritsar.
}

\begin{abstract}
Self-Inflicted or Fabricated injuries are a major problem which the doctors are facing during their duty. No authentic criteria has been so far devised to level an injury as fabricated one. Out of total 1056 cases of assault resulting in mechanical injuries which were examined in Govt. Medical College, Amritsar, Punjab 156 cases were diagnosed as being fabricated injuries sustained to support false charges of assault. In the present study an attempt has been made to collect the various parameters of fabricated-injuries which may be quite helpful to the doctors, lawyers, judiciary and other law enforcing agencies.
\end{abstract}

Keywords: Fabricated injury, Self-inflicted injury, Fictitious injuries, Grievous Hurt.

\section{Introduction}

Fictitious injuries are also called Forged or fabricated injuries. Wounds inflicted by a person on his own body are called Self-inflicted wounds (1) or caused by another acting in agreement with him (Self-Suffered Injuries)(2). The definition of self-injurious behavior applies to persons who hurt or harm themselves without the motives of suicide or of sexual-deviation. The behavior of persons who inflicted bodily injury and pain upon themselves includes a variety of reactions and is known by various names, such as masochistic behavior, selfpunishment, self-directed aggression and self-injury. This behavior has a very wide range, including scratching of adolescent acne, nail biting, lip and tongue chewing, hair pulling (trichotillomania), inflicting of wounds on the skin with sharp instruments, burning of the skin with cigarettes and head banging (3).

These simulating homicidal wounds are usually produced to support false charge of assault or attempted murder against an opponent to augment seriousness of injuries which one has already received during assault, to prove self-defense or to substantiate a charge of violence. (1).

Motive for fabricated/self inflicted injuries may be due to following reasons: -

1. To support a false charge against another person with ulterior motive.

2. To avert suspicion

3. To charge an enemy with assault or attempted murder.

4. To make simple injury appear serious.

5. By assailant to pretend self-defense or change appearance of wound, which might connect with the crime.

6. By police man and watch man acting in collusion with robbers to show that they were defending the property.

7. By prisoners, to bring a charge of beating against the officer.

8. By recruits to escape military services. (4)

\section{Aims And Objectives}

Aim of this study is to identify and collect the various parameters of an alleged fabricated injury using scientific methods. The objective was to know reasons for increased incidence for fabricated injuries and to look for underlying causes for this in human practice. The manner in which fatal injuries are inflicted i.e whether self-inflicted or inflicted by another person/persons or by accident, is a problem faced by the Forensic Pathologists, the police and the coroner. Some cases cannot be resolved by mere study of the pattern of injuries and resolution may be difficult or impossible in a small number of cases even after examination of the scene of the crime and all other available evidence. Furthermore in the absence of conclusive evidences, it becomes a problem for medical fraternity and law enforcement agencies. This study is an attempt to provide certain guidelines from the study of alleged fabricated injuries. 


\section{Material \& Methods}

Out of total 1056 medicolegal cases only 156 cases of alleged fabricated injuries or suspected fabricated injuries coming to the emergency wing of SGTB Hospital and GND hospital, Amritsar were studied from 06.06.1997 to 12.9.2013. The study includes the detailed bio-data of the cases. Detailed particulars of all the injuries were recorded in the proforma. Findings, X-rays and photographs were taken to make the study more scientific. Present study was conducted on mentally sound individuals where no history of any major psychiatric illness was recorded in any case. History of some psychiatric illness, intake of some intoxicant which was vital in every alleged case of fabricated injury along with previous history of fabricated injuries if any were also recorded. History of details of incidence, different ages of the wound and different kinds of weapons used were important observations made from the study of injuries in relation to fabricated injuries. All above mentioned parameters were taken into consideration to arrive at a proper conclusion regarding the fabricated injury.

\section{Observations}

Observations of study of 156 alleged fabricated medicolegal cases were as under -

\subsection{Incidence of alleged fabricated injuries in relation to total number of medicolegal cases.}

\begin{tabular}{|l|l|l|}
\hline $\begin{array}{l}\text { Total no. of medico-legal cases } \\
\text { reported }\end{array}$ & $\begin{array}{l}\text { Total no. of alleged fabricated injury } \\
\text { cases }\end{array}$ & Percentage \\
\hline 1056 & 156 & 14.77 \\
\hline
\end{tabular}

Table I showing incidence of alleged fabricated medicolegal cases

Table I shows that 1056 medico-legal cases were examined out of which $156(14.77 \%)$ cases of alleged fabricated injuries were selected for study.

\subsection{Age and Sex wise distribution of alleged fabricated injury cases.}

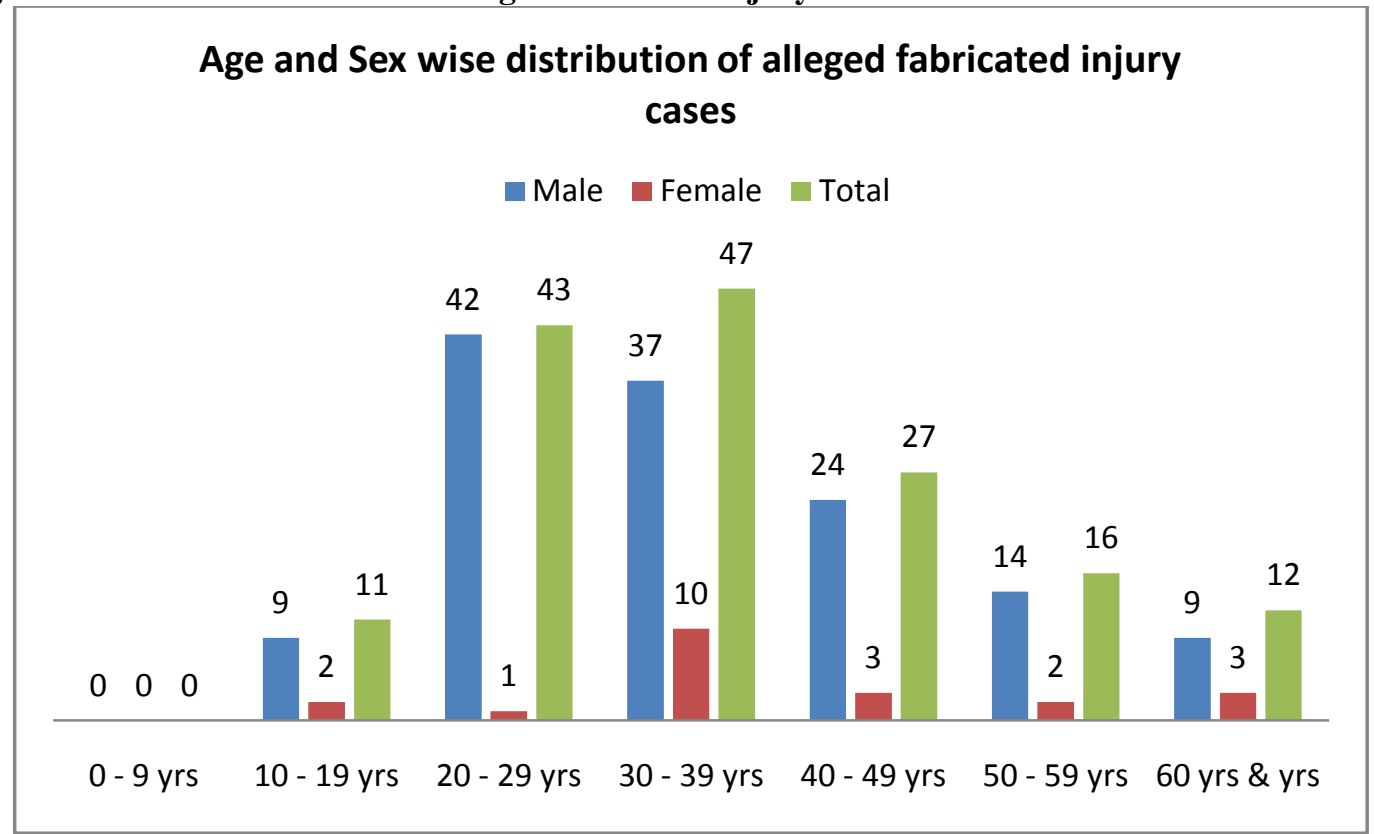

Chart No. I showing Age and Sex wise distribution of alleged fabricated injury cases.

Chart No.I shows males $(86.54 \%)$ dominance over females $(13.46 \%)$ inflicting alleged fabricated injuries. Maximum number of cases were in the age group of 30-39 years (30.13\%) following closely was the age group 20-29 years (27.56\%). Total No. of patients in the young age group of 20 to 39 years were 90 (57.69\%). Least number of cases were recorded in the extremes of ages. Total mean age in both sexes was 36.55 years, whereas the mean age of female was 39.69 years and that of male was 36.06 years. 
4.3 Occupation of individuals to have suffered fabricated injury (ies).

\section{Occupation of individuals to have suffered fabricated injury \\ (ies)}

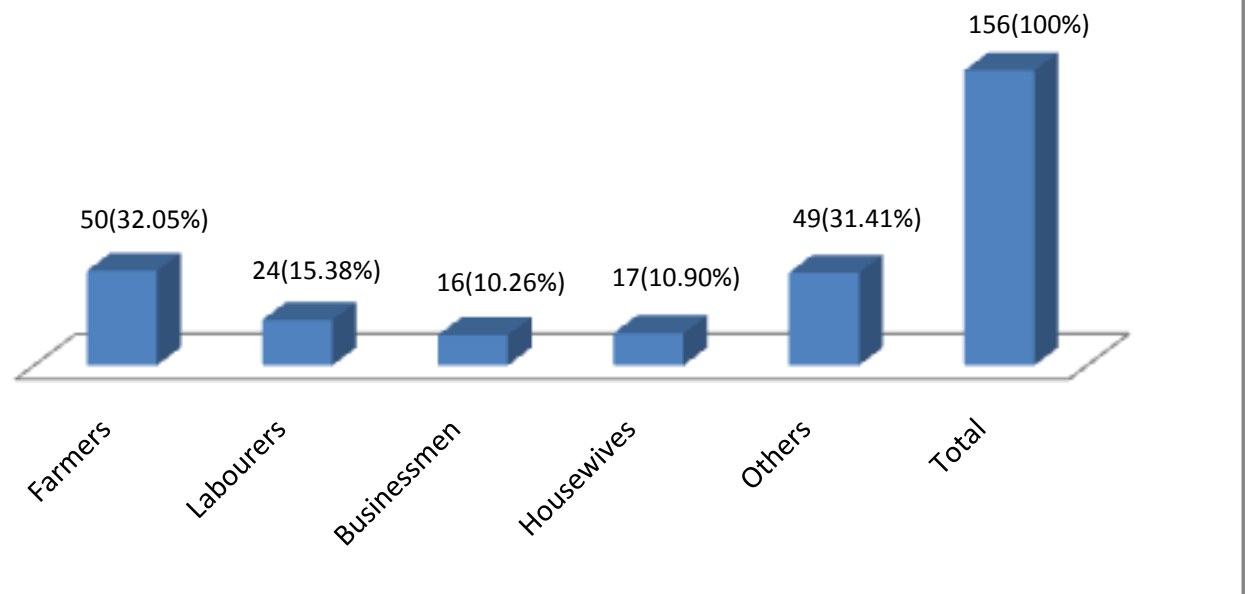

Chart No. II showing Occupation of the individuals alleged to have suffered fabricated injury (ies)

Chart No. II shows that the farmers are more commonly involved in the process of alleged fabrication of the injuries $(32.05 \%)$ followed by labourers $(15.38 \%)$ and businessmen $(10.26 \%$. Housewives are not legging behind with $10.90 \%$ of total recorded cases of fabricated injuries.

\subsection{Distribution of Alleged fabricated injury cases in relation to cause of dispute.}

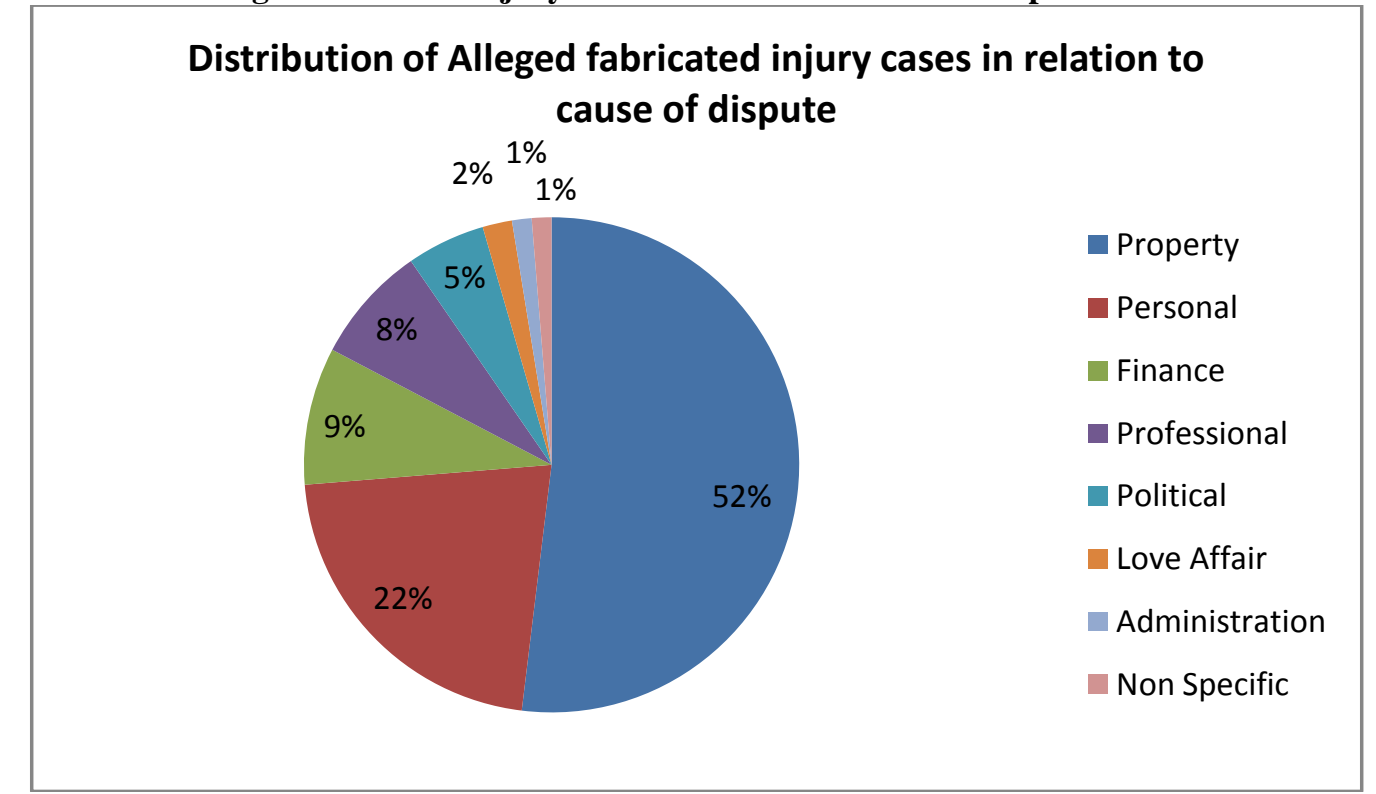

Chart No.III showing Distribution of Alleged fabricated injury cases in relation to cause of dispute.

This study in chart No. III shows that the most common cause for dispute is real estate property $(51.92 \%)$ and personal $(21.79 \%)$. The personal matters being of secret nature were not divulged by the concerned individual alleged to have caused the fabricated injury. Financial matter $(9.61 \%)$ was another cause for inflicting fabricated injuries in which lending and borrowing of money was involved. In the professional jealousy $(7.69 \%)$, the disputes regarding the clash of common interests were involved. Clashes between various political parties $(5.12 \%)$ and Love affair $(1.92 \%)$ were other reason for inflicting the fabricated injuries. 


\subsection{Distribution of alleged fabricated injuries as per Anatomical sites}

\section{Distribution of alleged fabricated injuries as per Anatomical sites}

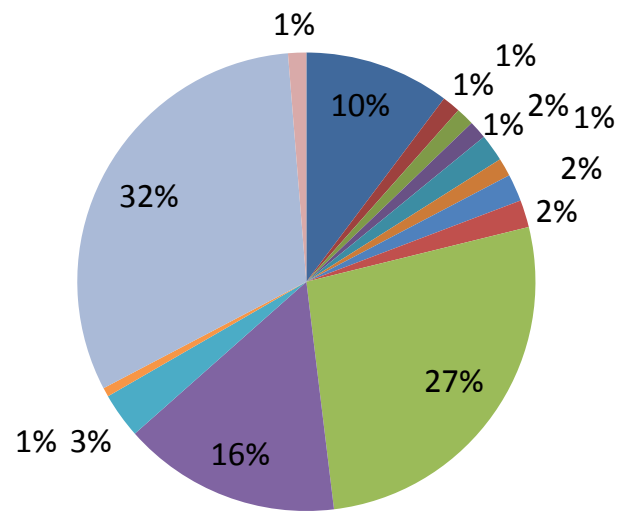

$$
\begin{array}{ll}
\square \text { Head } & \text { Face } \\
\square \text { Forehead } & \text { Tooth } \\
\square \text { Chest } & \text { Back } \\
\square \text { Abdomen } & \text { Arm } \\
\square \text { Forearm } & \text { Finger } \\
\square \text { Thigh } & \text { Knee } \\
\square \text { Leg } & \text { Toe }
\end{array}
$$

\footnotetext{
Chart No. IV showing Distribution of alleged fabricated injuries as per Anatomical sites
}

Chart No. IV Shows the distribution of the injuries according to the Anatomical sites. The most preferred sites for fabrication were the non-vital parts of the body i.e. legs account for $31.41 \%$, forearms for $26.92 \%$ and fingers for $15.38 \%$ (Total 80.75\%). Vital parts of the body like head $10.26 \%$ Face $1.28 \%$ (Total $19.25 \%$ ) were among least preferred areas for fabrication of injuries.

\subsection{Type of fabricated injuries according to mechanical classification.}

\begin{tabular}{|l|l|l|l|l|l|}
\hline Sr. No. & Type of Injury & No. of Cases & $\%$ age & Fractures & $\%$ age \\
\hline 1 & Abrasions & 2 & 1.28 & - & - \\
\hline 2 & Contusions or Bruises & 6 & 3.85 & 5 & 3.2 \\
\hline 3 & Lacerated Wounds & 13 & 8.33 & 11 & 7.05 \\
\hline 4 & Dislocation of bone/tooth & 4 & 2.56 & - & - \\
\hline 5 & Incised wounds & 121 & 77.56 & 116 & 74.36 \\
\hline 6 & Stab wounds & - & - & - & - \\
\hline 7 & Firearms & 10 & 6.41 & - & - \\
\hline Total & & 156 & 100 & 132 & 84.62 \\
\hline
\end{tabular}

Table II showing Type of fabricated injuries according to mechanical classification

Table II shows the relationship of alleged fabricated injuries with types of injuries according to their mechanical-classification. Maximum number of alleged fabricated injuries recorded were incised wounds $(77.56 \%)$ followed by lacerated wounds $(8.33 \%)$, abrasions $(1.28 \%)$ and bruises $(3.85 \%)$ were the other injuries. Not even a single case of stab wound was reported in this study. Fractures were seen in $84.62 \%$ cases. No fracture was seen in firearm injuries $(6.41 \%)$ and abrasions $(1.28 \%)$.

4.7 Number of Alleged fabricated injuries in an individual case

\begin{tabular}{|l|l|l|}
\hline No. of Injuries & Number of Cases & $\%$ age \\
\hline One & 123 & 78.85 \\
\hline Two & 20 & 12.82 \\
\hline Three and More & 13 & 8.33 \\
\hline Total & 156 & 100 \\
\hline
\end{tabular}

Table III showing Number of Alleged fabricated injuries in an individual case

Table III shows that the fabricators preferred only single alleged fabricated injury in majority of the cases $(78.85 \%)$. Multiple alleged fabricated injuries i.e three or more were recorded in $8.33 \%$ cases only. 
4.8 Direction of the Alleged fabricated injury/injuries

\begin{tabular}{|l|l|l|}
\hline Direction & No. of Cases & $\%$ age \\
\hline Horizontal & 93 & 59.62 \\
\hline Oblique & 37 & 23.72 \\
\hline Vertical & 10 & 6.41 \\
\hline Diffuse & 6 & 3.85 \\
\hline Circular & 10 & 6.41 \\
\hline Total & 156 & 100 \\
\hline
\end{tabular}

Table IV Showing Direction Of The Alleged Fabricated Injury/Injuries

Table IV shows that the most of the individuals sustained horizontal cuts $(59.62 \%)$ and oblique cuts $(23.72 \%)$ on their bodies. Circular cuts $(6.41 \%)$ were seen in firearm injuries and diffuse swelling in $3.85 \%$ in Bruises or contusions, vertical cuts were also seen in $6.41 \%$ cases.

4.9 Alleged fabricated injuries in relation to the accessibility of part injured.

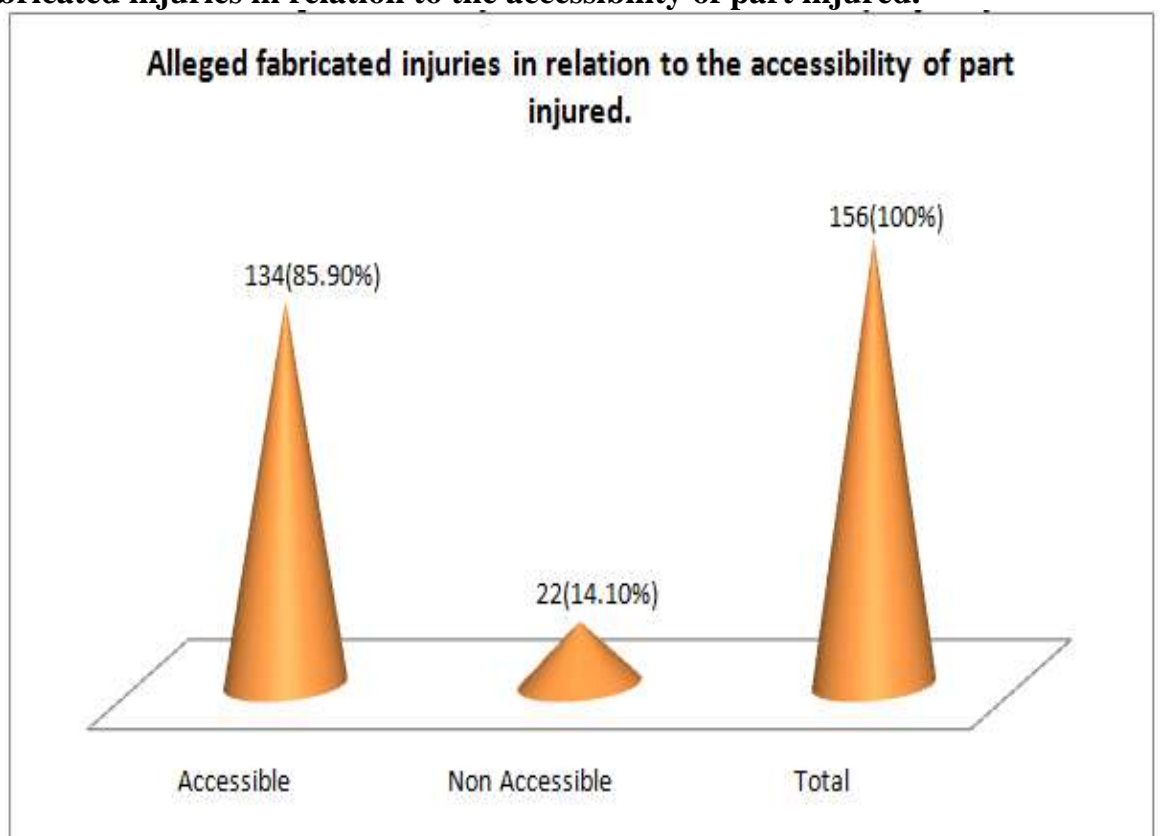

Chart No. V showing Alleged fabricated injuries in relation to the accessibility of part injured.

Chart No. V shows that in majority of cases $(85.90 \%)$ injured part of the body was easily accessible, and only in $(14.10 \%)$ cases, the body part was non-accessible.

\subsection{Cuts/Tears on the clothing of the victim corresponding to the Alleged fabricated injury}

\begin{tabular}{|l|l|l|}
\hline Cuts on clothes & No. of Cases & $\%$ age \\
\hline Present, corresponding to the injury & 24 & 15.38 \\
\hline Absent, no cuts in the clothing & 132 & 84.62 \\
\hline Total & 156 & 100 \\
\hline
\end{tabular}

Table V showing Cuts/Tears on the clothing of the victim corresponding to the Alleged fabricated injury.

Table V shows that in majority of cases $(84.62 \%)$ the clothes did not show any cut, corresponding to injuries.

\subsection{Types of weapon used for inflicting alleged fabricated injuries.}

\begin{tabular}{|l|l|l|}
\hline Weapon used & No. of Cases & $\%$ age \\
\hline Sharp & 115 & 73.72 \\
\hline Blunt & 24 & 15.38 \\
\hline Firearm & 17 & 10.90 \\
\hline Pointed & 00 & 00 \\
\hline Total & 156 & 100 \\
\hline
\end{tabular}

Table VI showing Types of weapon used for inflicting alleged fabricated injuries.

Table VI shows that in commonest weapons used for inflicting fabricated injuries were sharp edged weapon in $73.72 \%$ of cases and least were the firearm injury cases $10.90 \%$. No case of alleged fabricated injury by pointed weapon was recorded. 


\subsection{History consistent with alleged fabricated injury or not.}

\section{History consistent with alleged fabricated injury or not}

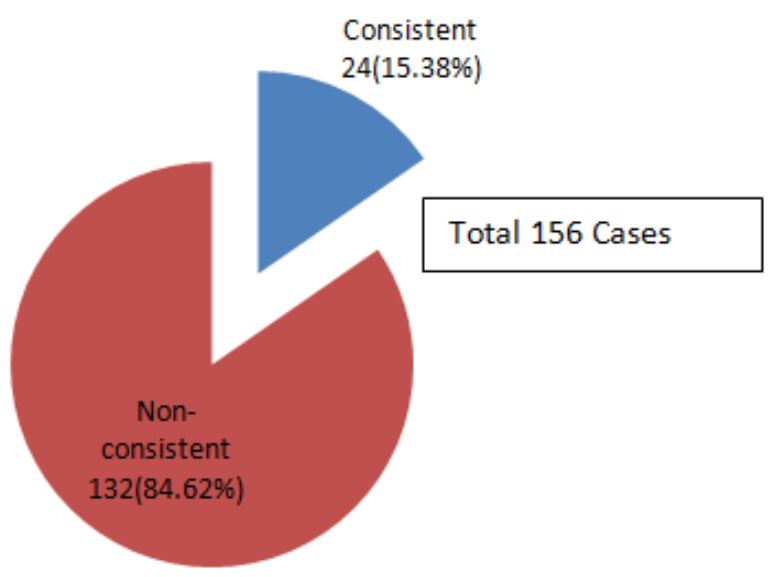

Chart No. VI showing History consistent with alleged fabricated injury or not.

Chart No. VI shows that in $132(84.62 \%$ ) cases, the history of the injury caused by the weapon ( as narrated by the injured) was not compatible with the type and direction of the injury observed. History of the case also included the type of weapon used for inflicting injury(ies), position of victim (sufferer); position of the assailant, number, age, size and depth of injuries received and the position of clothes.

\subsection{The age/duration of Alleged fabricated injury}

\begin{tabular}{|l|l|l|}
\hline Age/Time in hours & No. of Cases & $\%$ age \\
\hline Fresh & 128 & 82.05 \\
\hline Within 6 hours & 17 & 10.89 \\
\hline $6-12$ & 4 & 2.57 \\
\hline $12-24$ & 4 & 2.57 \\
\hline $24-48$ & 3 & 1.92 \\
\hline Total & 156 & 100 \\
\hline
\end{tabular}

Table VII showing The age/duration of Alleged fabricated injury

Table VII shows that the distribution of age/duration of injury. In majority of the cases $(82.05 \%)$ the age of the injuries was fresh because of profuse bleeding at the site (within a few minutes) and within 6 hours in only $(10.89 \%)$ cases. Thus, total duration of majority of cases $(92.94 \%)$ was within few minutes to within 6 hours.

\subsection{Distribution of depth of alleged fabricated injuries}

\begin{tabular}{|l|l|l|}
\hline Depth & No. of cases & $\%$ age \\
\hline Skin deep & 2 & 1.28 \\
\hline Muscle deep & 18 & 11.54 \\
\hline Bone Deep & 132 & 84.62 \\
\hline Dislocation & 4 & 2.56 \\
\hline Total & 156 & 100 \\
\hline
\end{tabular}

Table VIII showing Distribution of depth of alleged fabricated injuries

Table VIII shows the distribution of injuries according to their depth. The study is showing that majority of the fabricated injuries were bone-deep (84.62\%) and in $2.56 \%$ cases even the dislocation of tooth was observed.

4.15 Nature of alleged fabricated injuries

\begin{tabular}{|l|l|l|}
\hline Nature of injury & No. of Cases & \% age \\
\hline Simple & 20 & 12.82 \\
\hline Grievous & 133 & 85.26 \\
\hline Dangerous to life & 3 & 1.92 \\
\hline Total & 156 & 100 \\
\hline
\end{tabular}

Table IX showing Nature of alleged fabricated injuries 
Table IX shows that in majority of the cases $(85.26 \%)$ the alleged fabricated injuries were grievous in nature whereas, it was dangerous to life in only $1.92 \%$ of cases.

\subsection{Distribution of self-suffered and self-inflicted injuries}

\section{Distribution of self-suffered and self-inflicted injuries}

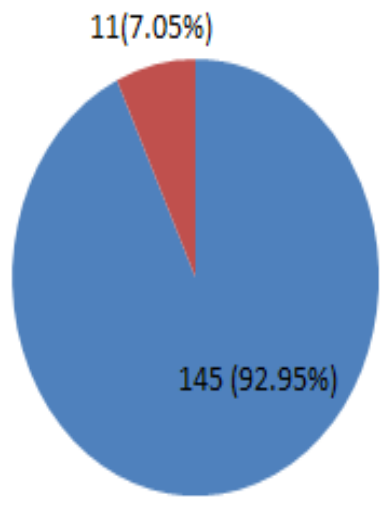

Total Allegedly Fabricated

Cases $=156$

Chart No. VII showing Distribution of self-suffered and self-inflicted injuries

Chart No. VII shows the distribution of study of injuries whether they are self-inflicted or self-suffered. The study showed that in majority of the cases $(92.95 \%)$ these were self-suffered injuries, while self-inflicted injuries were recorded only in $7.05 \%$ cases.

\section{Discussion}

The study of 156 cases were conducted which were suspected to be the cases of fabricated injury. The study is supported with medico-legal injury reports, photographs and x-rays etc .

\section{Incidence:}

According to a study conducted by Philips and Muzaffer $(1961)^{5}$, in psychiatric hospitals the incidence of self-injury was $4.29 \%$ among adults, out of which $2.17 \%$ were men and $6.1 \%$ were women, whereas Deopfmer $(1962)^{6}$ recorded $0.34 \%$ incidence in general population. In another study conducted by Olsen $(1967)^{7}$, the incidence of self-injury was recorded as $0.5 \%$ in normal adult population, whereas, our study shows that the incidence of alleged fabricated injuries in general population is $14.77 \%$ which is significantly higher than above mentioned studies because of different socio-economic and political conditions in our country.

\section{Age}

Olsen $(1967)^{7}$ had recorded that the majority of cases of self-inflicted injuries were in the age group of 15-30 years and the average age was 24 years, whereas Simpson et al $(1983)^{8}$ had shown that injuries were the leading cause of death among American-Indians in the age group of 15-25 years, which constitute only a quarter of population accounting for $46 \%$ of all injuries. This specific age group had high rates of self-inflicted injuries, crashes and assaults whereas, this study has shown that maximum number of alleged fabricated injuries were inflicted in the age group of 30-39 years(30.13\%) and next group commonly involved was 20-29 years $(27.56 \%)$, middle aged and young people falling in the age group of 20-39 years constitute $57.69 \%$ of all the alleged fabricated injury cases. The alleged fabricated injuries were rare in the extremes of ages. The mean age of females was 39.69 years while that of males was 36.06 years. The total mean age of the cases was recorded as 36.55 years, much higher than that of 24 years observed by Olsen (1967) ${ }^{7}$. The age factor was quite variable, youngest recorded case was of 17 years and the oldest was 80 years.

\section{Sex}

In a study conducted by Harold and Benjamin $(1991)^{9}$, the male and female ratio of self-injury in psychiatric hospitals was recorded as 1:3, whereas the present study shows that male and female ratio 6.43:1. The high incidence among males is probably due to strong male chauvinistic factor in our country. Bonte $(1996)^{10}$ has also observed that male sex was more commonly involved in undergoing self-mutilations, which is compatible with our observations. Contrary to our findings were the observations made by Gunn et al (1993) ${ }^{11}$ 
amongst the sentenced prisoners where the lifetime prevalence of deliberate self-harm was $32 \%$ in women and $17 \%$ in men.

\section{Occupation}

As per Chart II, the present study shows that people from almost every profession were involved in the practice of inflicting alleged fabricated-injuries. But the farmers $(32.05 \%)$ followed by labourers $(15.38 \%)$, housewives (10.90\%) and businessmen (10.26\%) were leading than others like shopkeepers, servicemen, goldsmith, unemployed and retired persons, whereas Bonte $(1996)^{10}$ observed that nearly $1 / 3^{\text {rd }}$ people who performed self-mutilations belonged to the medical profession which is not compatible with our study.

\section{Causes of dispute}

Wilkins and Coid (1993) concluded that self-mutilations is an indicator of severe psychopathology, mostly antisocial and /or borderline personally disorder. Bonte (1996) ${ }^{10}$ pointed out that the reason for selfmutilation was to receive compensation from private accident insurance company. Analysis of Chart III shows that the present study differs from above mentioned author's observations, the main causes for inflicting alleged fabricated injuries were various type of disputes. Most common cause is the real estate property (51.92\%), personal disputes $(21.79 \%)$ followed by financial disputes $(9.61)$, professional jealousies $(7.69 \%)$, political rivalries $(5.12 \%)$, love affairs $(1.92 \%)$ and administrative problems $(1.28 \%)$.

\section{Anatomical sites}

Graff and Mallin (1967) ${ }^{12}$ observed that wrist cutting is frequent in psychiatric hospitals and occurs more often in women. According to Mant (1984) ${ }^{13}$, the most common non-fatal injuries consist of a number of superficial incisions across the front of the wrist but may appear elsewhere on the body. Bonte (1996) ${ }^{10}$ observed that self-mutilations were performed commonly on a single or multiple fingers and rarely on hands, forearms or legs. Whereas according to Chart IV, in our study, the legs $(31.41 \%)$ were the commonest site for self-inflicted/self-suffered injuries followed by back of forearm $(26.92 \%)$ and the fingers of the hand $(15.38 \%)$. The peculiar observation regarding the site of injuries is that on the legs and forearm, the injuries were mainly confined to the body part where bone is more prominent or in other words is easily accessible and these injuries mimick the defence wounds. Injuries on the vital parts head $10.26 \%$, chest $1.92 \%$, forehead $1.28 \%$, face $1.28 \%$ were rarely seen. Fabricated injuries on head are inflicted with the intentions of getting legal benefits of section 307 of the IPC, (dangerous to life injury) and to allay the suspicion of fabricated injuries. Fabricated injuries on the face were inflicted with the aim of getting legal benefits of Grievous hurt acts (Section 325/326 IPC) (Lal and Lal, 1982) ${ }^{14}$. Even non-accessible vital part like back $(1.28 \%)$ was not spared for inflicting fabricated injuries. Loose tooth $(1.28 \%)$ was also removed with the same intentions. According to Chanana and Kalra, $(2014)^{15}$ If trauma presents along with poor oral hygiene and no fracture of thin alveolar bone (associated with traumatized tooth) then it may go in favor of fabricated story of trauma furnished by the patient..

\section{Number of injuries}

According to Greval $(1953)^{16}$, the fabricated bruises are always single. Suicidal cuts are multiple and parallel in nature (Mant, 1984) ${ }^{13}$. Our study as per Table III, shows that most of the sufferer/victim $(78.85 \%)$ preferred only single alleged fabricated injury, suggesting that majority of the people want to get maximum benefits from minimum number of injuries. Three or more alleged fabricated injuries were recorded in only 8.33\% cases. No case of suicidal cuts was observed in this study as observed by various authors (Fatteh, 1973;

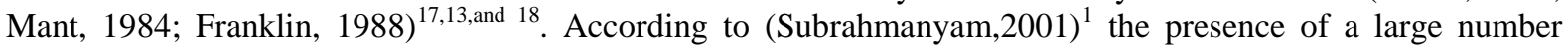
superficial wounds is presumptive evidence of self-infliction.

\section{Direction}

As per table IV, this study shows that most of the individuals preferred horizontal cuts (59.62\%) and oblique cuts $(23.72 \%)$. Vertical cuts $(6.41 \%)$ were the least preferred. Circular shape of the injury was observed in $(6.41 \%)$ cases as these were firearm-injuries, and in bruises/contusions it was diffuse $(3.85 \%)$ cases. Horizontal cuts and the oblique cuts are more in favour of the alleged fabricated injuries. Horizontal cuts are planned cuts in comparison to the oblique cuts. Oblique cuts which gives rise to suspicion that the injury may not be an alleged fabricated injury, but if we take into consideration the other facts, it indicates that the oblique cuts were too, the alleged fabricated injuries. The most confusing picture is in relation to the vertical cuts, which are usually produced on the skull and in such cases, to access regarding the homicidal or fabrication of injury needs meticulous examination alongwith detailed history and keeping in view the other factor, the exact conclusions can be drawn. Bonte $(1996)^{10}$ also observed that majority of the self mutilations in the form of incised wounds were either horizontal or oblique cuts. 


\section{Accessibility of the part injured}

Smith \& Fiddes $(1955)^{19}$ and Simpson $(1975)^{20}$ described suicidal stab wounds of the neck as rare, but Gee $(1972)^{21}$ has quoted that self-inflicted stab wounds of the neck were an acceptable mode of suicide in ancient Rome. West $(1981)^{22}$, observed that the suicidal stab wounds are usually seen on areas of body overlying vital organs and he simultaneously concluded that certain sites of the body would be impossible targets for suicidal injury or self-inflicted injury i.e, back of chest, abdomen, buttocks etc. In our study, as per Table II, no case of stab wound was recorded but as per Chart V in $85.90 \%$ of cases the injured part of the body was easily accessible for inflicting alleged fabricated-injury which is the peculiar feature/parameter of this study.

\section{Injuries on clothes}

Our findings, cuts on clothes corresponding to injuries were absent in $84.62 \%$ cases similar to that observed by Smith (1949) ${ }^{23}$. According to Smith \& Fiddes (1955) ${ }^{19}$, if the only clothes are damaged then that, in itself is a suspicious matter for it is extremely difficult to fire a shot through the clothing without causing any injury to the skin. To fire a shot through the clothing, the fabricator must either hang them up or fire through them while wearing them but escaping the bodily injury.

On further analysis of the findings of the table V, it was observed that in only $15.38 \%$ cases cuts on the clothes were present corresponding to the injuries. This further indicates that the professionalism and criminalization of mind of both fabricator and the victim involved in the fabrication of the injuries.

\section{Weapon}

According to a study conducted by Conn et al $(1946)^{24}$, self injuries are more commonly produced by simple nail scratching or by cutting or pointed instruments. Whereas, according to the study of Johnson $(1973)^{24}$; male prisoners used razor blade or other sharp objects (often specially designed) causing self-inflicted injuries. Harold and Benjamin (1991) ${ }^{9}$, showed that self-injury is inflicted with a razor blade, knife broken glass or mirror. As per table VI, our study also shows the same observations as that of Johnson (1973) ${ }^{25}$ and Harold \& Benjamin $(1991)^{9}$, where sharp edged weapons were used in $(73.72 \%)$ of cases, blunt weapons in $15.38 \%$ and firearms in $10.90 \%$ of alleged fabricated injuries. Bonte $(1996)^{10}$ observed that the people used axes and circular or chain saws for inflicting self-mutilations while single injury caused by sharp edged weapon, amongst the group of injuries caused by blunt or other weapons especially on the selected sites as observed in the study (Table VI) are highly suspicious and are in favor that of particular injury by sharp edged weapons, may be an alleged fabricated injury.

\section{History}

As per Chart VI in this study, In most of the cases (84.62\%), history of the case was not consistent with the alleged fabricated injuries. The sufferer/victim used to narrate their concocted story just to mislead the doctors conducting medicolegal examination and also to the police.

\section{Injuries}

As per table II, the present study of alleged fabricated injuries indicates that $77.56 \%$ of the injuries were incised wounds, similar to that observed by Greval $(1953)^{16}$ and Mant $(1984)^{13}$. Lacerated wounds and contusions are not the commonly observed fabricated injuries, even in our study it accounted for $8.33 \%$ and $3.85 \%$ of the injuries respectively. These findings supports the observation of Smith and Fiddes $(1955)^{19}$ i.e they too, concluded from their study that lacerated wounds and contusions are rarely fabricated injuries. Maximum percentage of fracture individually was recorded in incised wounds $(95.87 \%)$, followed by lacerated wounds $(84.61 \%)$ and in bruises in $83.33 \%$ cases. However according to (Subrahmanyam,2001) ${ }^{1}$ contusions and lacerations are rarely self-inflicted.

\section{Age of injury}

In a study conducted by Olsen $(1967)^{7}$, he found that most of the self-inflicted injuries were fresh. As per table VII, in the present study, we also observed similar findings that in majority of cases $(92.94 \%)$, the alleged fabricated injuries were fresh means within a few minutes to within 6 hours. Even if the time of incidence was not recorded but this was evident that most of the alleged fabricated injuries were fresh in nature whereas the actually caused injuries i.e, injuries inflicted during scuffle or at the time of incidence, were of longer duration. In other words the age of self-inflicted/self-suffered injuries did not coincide with the age of other injuries on the body of the person examined which gives rise to suspicion that the fresh injuries were fabricated ones. 


\section{Depth of injuries}

According to Smith and Fiddes $(1955)^{19}$, self-inflicted wounds were extremely superficial and skin deep while our study has shown a different picture, as per Chart VIII, 84.62\% alleged fabricated injury cases reported in our hospital were having cut fractures i.e bone-deep injury, $11.54 \%$ were muscle deep and $1.28 \%$ was skin deep and another $2.56 \%$ was dislocation of small bone and teeth. The other main reason for the fabrications was to counteract the legal benefits of the opposite party. People in apprehension gets compelled to inflict fabricated injuries to prove that the other party was also using aggressive means and they, sufferer/victim was acting in self-defence.

\section{Nature of injuries}

As per table IX, the present study shows that in majority of cases $(85.26 \%)$ the alleged fabricated injuries were declared as grievous in nature, whereas in three case $1.92 \%$ it was dangerous to life, in only $12.82 \%$ cases the injuries were declared as simple. According to Mant $(1984)^{13}$, most of the self-inflicted injuries are superficial which is not compatible with our study. The probable cause of this reverse trend is the punishment for inflicting simple injury in our country is only one year rigorous imprisonment or fine upto one thousand rupees or both (section 323 IPC) (Lal and Lal, 1982) ${ }^{14}$. To get legal benefits of grievous hurt which carries heavy punishments, it is grossly being misused.

\section{Self-suffered or self-inflicted injuries}

Present study (Chart VII) shows that majority of cases $(92.95 \%)$ were suffering from alleged fabricated self-suffered injuries, while only $7.05 \%$ were suffering from alleged fabricated self-inflicted injuries. Though no comparative study between self-inflicted and self-suffered injuries is available, but keeping in mind the study of Olsen $(1967)^{7}$ and Mant $(1984)^{13}$ which shows high incidence of self-inflicted injuries in general populations, this ratio (13.1:1) does not present the true picture of our society. The probable cause of less number of selfinflicted injuries was the less number of psychiatric individuals reported in our hospitals and furthermore our study was not in relation to psychiatric patients but included only mentally sound individuals.

\section{Summary And Conclusions}

Present study is an attempt to collect various parameters of an alleged fabricated injury. The various parameters collected are based on the data and observations of this study, as follows :-

1. Incidence of alleged fabricated injuries was recorded as $14.77 \%$ which is significantly higher.

2. The people who suffered alleged fabricated injuries were from almost all age groups, young as well as old (17 to 80 years). Maximum number of cases (57.69\%) were in the age group of 20 to 39 years. Mean age of female was 39.69 years while that of males was 36.06 years.

3. Sufferers were commonly males $(86.54 \%)$ as compared to females $(13.46 \%)$.

4. People from almost every field/profession are involved in undergoing alleged fabricated injuries. Farmers $(32.05 \%)$, labourers (15.38\%), housewives (10.90\%) and businessmen (10.26\%) were leading, even shopkeepers, servicemen, goldsmith and unemployed were not lagging behind.

5. The main causes for suffering alleged fabricated injuries were disputes related to real estate property $(51.92 \%)$, personal $(21.79 \%)$, finance $(9.61 \%)$, professional jealousies $(7.69 \%)$ and political rivalries $(5.12 \%)$ etc.

6. In $85.90 \%$ cases, the injured part of body was easily accessible. Commonly preferred sites for undergoing alleged fabricated injuries were non-vital and easily accessible parts of body like legs (31.41\%), forearms $(26.92 \%)$ and fingers $(15.38 \%)$. The injuries on vital parts of the body, though dangerous, were rarely performed.

7. Most of the victims (78.85\%) preferred only single alleged fabricated injury on their bodies. Three or more alleged fabricated injuries were rare $(8.33 \%)$.

8. Individuals preferred horizontal cuts $(59.62 \%)$ and oblique cuts $(23.72 \%)$ on their bodies.

9. In $84.62 \%$ cases, cuts in the clothes were either absent or not corresponding to the injury site. In only $15.38 \%$ of cases, cuts on the clothes were corresponding to the injuries.

10. In $73.72 \%$ cases, people used sharp edged weapons. In $10.90 \%$ cases, people used firearms for inflicting alleged fabricated injuries.

11. In $84.62 \%$ cases, the history was not consistent with the alleged fabricated injuries.

12. In $92.94 \%$ cases, the age of alleged fabricated injuries was within a few minutes to within 6 hours.

13. Maximum number of alleged fabricated injuries recorded were incised wounds $73.72 \%$.

14. The depth of alleged fabricated injuries was bone deep in $84.62 \%$ cases, so fractures were recorded in $84.62 \%$ of alleged fabricated injuries. No fracture was seen in firearm injuries and abrasions.

15. The nature of alleged fabricated injuries was grievous in $85.26 \%$ cases and dangerous to life in $1.92 \%$ cases. 
16. Most of the alleged fabricated injuries were self-suffered (92.95\%) while self-inflicted injures were recorded only in $7.05 \%$ of cases.

\section{Suggestions}

The alleged person who has fabricated injuries is involved in the crime by harming himself, enhancing gravity of the crime against the accused who might not have used any dangerous weapon and thereby misleading the police by giving false information. The victims of fabricated injuries are normally booked under section 323/324 IPC and or 325/326 IPC and minimum punishment under these section is imprisonment for 3-7 years for causing hurt to others by dangerous weapons while the punishment under section 182 IPC is imprisonment for six months or with fine which may extend to one thousand rupees or with both, according to which whoever gives false information deliberately to misled police authorities. This law should be amended to avoid fabrication of mechanical injuries in the society. Doctors should be given more powers to declare such injuries as fabricated one in their medicolegal reports. Investigating authorities should register cases against the alleged accused persons causing grievous injuries only after going through proper investigation and taking into consideration the medicolegal opinion regarding fabrication of injuries and section 324/326 IPC should be made bailable offence. Law should be suitably amended to punish those involved in self-harm against the spirit of the constitution. Combined efforts of all the investigating agencies and doctors can help to avoid fabrication of injuries and will not only reduce unnecessary litigation in the court of law but also help in avoiding unnecessary harassment to innocent people.

\section{Bibliography}

[1]. Subrahmanyam, BV,Modi’s Medical Jurisprudence \& Toxicology,22th Edition, Butterworths. 2001 Page 386-388

[2]. Parikh, CK:,Mechanical injuries-Self inflicted wounds, Injuries - Medicoloegal aspects,Parikh's textbook of medical jurisprudence and toxicology,VIth Edition. C.B.S. Publsihers and distributors, 2014 , pp. 229-231.

[3]. Orian,C:,Self injurious behavior as a habit and its treatment.,Am. J. of Clinical Hypnosis Vol.32 (1) July, ,Imperial Printing Company, ST Joseph, Michigan, 1989, 49-85.

[4]. Reddy, KSN:,The essentials of forensic medicine and toxicology,Mechanical injuries.,33 ${ }^{\text {th }}$ Edition K.Sungun Devi, Malakbet, Hyderabad 2014,,p.3,4,134, 151.

[5]. Phillips, RH and Muzaffer, A:,Some aspects of self-mutilation in the general population of a large psychiatric hospital,Psychiatric Quarterly,1961, $35: 421-423$.

[6]. Doepfmer, R:,Arztl.Mitt., 1962. 47-59: 929,

[7]. Olsen,J:,Self-inflicted injuries ad false information to the police.,Medicine, Science and the Law,7(1): 1967. 22-25

[8]. Simpson, GS; Reid, R; Baker, SP; Teret, S:,Injuries among the Hopi Indians, ,J.A.M.A., 1983. 249: 1873-1876,

[9]. Harold, 1K ; Benjamin, JS:,Synopsis of psychiatry,Behavioural sciences, Clinical psychiatry, $6^{\text {th }}$ Edition. Williams and Wilkins, Boltimore, 1991. 559.

[10]. Bonte, W:,Medico-legal assessment of self-mutilations in cases of suspected insurance fraud,Institute of forensic medicine, Heinrich Heine University Dusseldorf, Germany, 1996.

[11]. Gunn et al:,Female offenders, 1991,Forensic Psychiatry, Clinical, Legal and Ethical Issues,Ist Edition. Hartnolls Ltd., Bodmin, Cornwell, UK, 1993, 616-18.

[12]. Graff,H and Mallin, R:,The synopsis of the wrist cutter,Am.J.Psychiatry, 1967. 124: 36-41

[13]. Mant, AK: Wound and their interprertion. Taylor's Principles and practice of medical jurisprudence.13 ${ }^{\text {th }}$ Edition. Churchill Livingstone, New York, 1984 pp. 169, 217, 218, 23, 238, 247.

[14]. Lal, RR and Lal, DKT:, The Indian penal Code (act XLV of 1860), $25^{\text {th }}$ Edition, Wadhwa Sales Corporation,Law Publishers, Dhantoli, Nagpur, 1982. pp. 268, 269,

[15]. Chanana Ashok and Kalra Sanjay 2014,International Journal of Science and Nature ,ISSN 2278-9103,IJSN, VOL 5(1) 2014: 177182

[16]. Greval,SDS:,Lyons Medical Jurisprudence for India, 10 Ed., , Thacker, Spink and Co., Ltd., 3 Esplande East, Calcutta ,1953 25374.

[17]. Fatteh.A:,Common types of cutting and stabbing wounds: ,Suicidal gunshot wounds, Handbook of forensic pathology,Ist Edition.,J.B.Lippincott Company, Philladelphia, U.S.A.,1973 pp.86-89 and 113.

[18]. Franklin, CA:,Injuries by mechanical violence, The medicolegal aspects of wounds,Medical jurisprudence and toxicology, $21^{\text {st }}$ Edition, N.M.Tripathi Pvt.Limited Bombay, 1988. pp.20-21, 252, 274, 275,

[19]. Smith, S and Fiddes, FS:,Self inflicted injuries, Wounds from firearms,Forensic Medicine- A test book for students and practitioners,J \& A Churchill Ltd. 104,10 ${ }^{\text {th }}$ Edition, Gloucester Place, WI 1955. pp. 167-172, 198-200,

[20]. Simpson, MA:The phenomenology of self-mutilation in a general hospital setting Canadian psychiatric Association Journal, 1975, 20: 424-434.

[21]. Gee.DJ:,Two suicidal transfixions of the neck, 1970,Medicine, Science and the Law, 1972 12 (3): 171-72,

[22]. West Iain :,Single suicidal stab wounds: A study of three cases,Medical Sci.Law, 1981. 21(3): 198-201.

[23]. Smith, S:,Forensic Medicine, $9^{\text {th }}$ Edition, London : Churchill, , 1949. p.168-173

[24]. Conn,JW; Johnston, MW and Conn, ES:,Ann.Intern.Med., 1946. 24, 487.

[25]. Johnson:,Secure Institutions, Forensic Psychiatry-Clinical Legal and ethical issue, 1973. 20:817-18. 